In deze rubriek komen onderzoekers aan het woord over participerende observatie. Zij doen verslag van hun eigen ervaringen en inzichten en volgen daarbij het spoor dat antropoloog Bronislaw Malinowski begin vorige eeuw uitzette. Geïnteresseerden kunnen contact opnemen met Joost Beuving: j.beuving@maw.ru.nl.

\title{
Scepsis, veldwerk en de bestudering van hedendaags sjamanisme
}

\author{
Jeroen Boekhoven *
}

In juni 2004, een paar maanden nadat ik was begonnen met mijn promotieonderzoek naar sjamanisme in Nederland, vertrok ik naar het Eigentijdsfestival. Op dit jaarlijkse evenement kunnen de 1750 bezoekers een weekend lang kennismaken met ongeveer vijfhonderd verschillende esoterische, spirituele en/of sjamanistische workshops en sessies. Voor mij was het dé kans om in een paar dagen tijd verschillende soorten sjamanisme te leren kennen.

De wereld die ik betrad was niet helemaal onbekend, want als student godsdienstwetenschap had ik de term sjamanisme leren kennen. Het staat voor activiteiten waarbij zogeheten sjamanen in een extatische toestand op reis gaan naar de goden- of geestenwereld om kracht, kennis of genezing te vinden. Een paar jaar na mijn afstuderen schreef ik bovendien een stuk over sjamanisme voor het tijdschrift van de Stichting Skepsis. Voor dat stuk bestudeerde ik literatuur om de waarheidsclaims van hedendaagse Nederlandse sjamanen te kunnen bekritiseren. Mijn scepsis ten opzichte van hun 'waarheid' was gebleven, maar als promovendus wilde ik actief participeren om sjamanisme in Nederland van binnenuit de begrijpen, te Verstehen.

Veldwerk organiseren was eenvoudig: voor het Eigentijdsfestival kon ik online een kaart kopen, en ook later in mijn onderzoek was meedoen veel makkelijker dan het ooit was voor de antropologen die sjamanisme wilden onderzoeken in exotische omgevingen in bijvoorbeeld Siberië, of Zuid- of Noord-Amerika. Toch nam ik - juist door mijn ervaringen tijdens veldwerk - al snel afstand van het idee om intensief veldwerk te doen. In dit artikel gaat het over die stap en de gevolgen ervan voor mijn onderzoek.

\section{In het veld}

Op het Eigentijdsfestival begon mijn sjamanenavontuur op vrijdagochtend in de tent van het zogeheten Asha Institute, met een workshop shu'em shamanism.

* Dr. Jeroen Boekhoven is als docent sociale wetenschappen verbonden aan de Academie voor Sociale Studies van de Hanzehogeschool Groningen. E-mail: j.w.boekhoven@pl.hanze.nl. 
Bezoekers werd verzocht ontspannen te gaan liggen op de matjes in het midden van de tent. De workshopleider en zijn studenten namen plaats in een kring om ons heen, en terwijl de workshopleider vertelde wat er zou gaan gebeuren, begonnen ze gezamenlijk te mediteren, te chanten en te trommelen.

In een met technische begrippen doorspekt verhaal legde de workshopleider uit wat de betekenis was van deze meditatie: hij vormde een soort elektromagneet met zijn leerlingen, en in het energetisch krachtenveld dat daarvan het gevolg was, konden wij onze rationele mindset verlaten om 'diepere dimensies van perceptie' te bereiken. Hij liet duidelijk merken dat hij was geïnitieerd in kennis die anderen (nog) niet hadden, bijvoorbeeld door te puffen en te steunen, waarmee hij - zo legde hij uit - de energiebanen in de tent reguleerde.

Het was een 'oeroude techniek' en geen new-agepraktijk, zo verzekerde hij ons. Nabespreken was niet de bedoeling, want dat zou ons juist weer naar onze dagelijkse 'dimensie van perceptie' voeren. De workshop was inderdaad rustgevend, zoals ook de latere meditatiebijeenkomsten van het Asha Instituut die ik bijwoonde. Zo ontspannend, dat ik bij latere bijeenkomsten steevast in slaap viel - en gewekt werd omdat mijn gesnurk het krachtenveld verstoorde.

Op vrijdagmiddag ging ik naar een van de zeven tipi's van de School voor Sjamanisme om te gaan trancereizen. Met hun trommels zouden zij ons helpen om in een trance te komen, die nodig was om rond te reizen in de magische onderwereld van natuurgeesten en -krachten. $\mathrm{Na}$ een rituele reiniging met de rook van brandende salie, het zogeheten smudgen, mochten we op matjes liggen, met gesloten ogen. Onder in de boom die we in gedachten moesten nemen, zouden we een deurtje kunnen vinden. Dat was de doorgang naar een wereld waarin we krachtdieren of power animals zouden kunnen ontmoeten. Mensen met meer ervaring, die hun krachtdier al kenden, konden de reis beginnen met een vraag in gedachten: de krachtdieren zouden hen helpen met het vinden van een antwoord.

Het idee erachter is dat de moderne mens het contact met de natuur is kwijtgeraakt. Die vervreemding zorgt voor persoonlijke en maatschappelijke problemen. Sjamanisme is erop gericht contact te leggen met de heilzame natuurkrachten waarvan de moderne mens vervreemd is. Sjamanistische technieken, zoals de reis naar die onderwereld, helpen het onmisbare contact te herstellen.

De reis zou ongeveer twintig minuten duren. Als de trommels zouden vertragen, was het tijd om terug te keren. Bij terugkomst, als we waren bijgekomen van de reis, zouden we onze ervaringen bespreken. Mijn eigen ervaringen staken bleek af bij die van de anderen, die hadden rondgereisd door prachtige landschappen en exotische dieren hadden ontmoet. Arenden, coyotes, panters, wolven of andere roofdieren waren gangbare krachtdieren. Sommige bezoekers waren onder de indruk van hun krachtdier, en wilden graag weten wat de betekenis daarvan was. Docenten vertelden ons dat we dat zelf moesten uitzoeken. Boeken over dieren konden helpen, maar uiteindelijk was de eigen intuïtie de beste bron van kennis. Bij latere bijeenkomsten van de School voor Sjamanisme merkte ik ook dat mijn gedagdroomde reiservaringen afweken van die van anderen. Opvallend was dat docenten en studenten van de School voor Sjamanisme hun ervaringen nogal verschillend interpreteerden: sommigen zagen sjamanisme als een vorm van psycho- 
therapie, en noemden zichzelf atheïst, anderen beschouwden hun krachtdier als een échte metgezel.

\section{Bomen en healen}

Heel anders was het bij sjamaan Searching Deer, die zijn workshop op het Eigentijdsfestival begon met een lezing over de heilzame kracht van bomen. Af en toe vroeg hij ons van onze stoelen op te staan, soms om mee te zingen, dan weer voor een oefening. Eén oefening was erop gericht om de levensboom in onszelf te ervaren. Hij vroeg ons onze armen te zwaaien als de takken van een boom. Op zijn vraag of iemand wel eens de energie van bomen had gevoeld, stak bijna iedereen in de tent de hand op. Bomen, zo legde hij uit, absorberen zware en sombere gevoelens, en ze stralen een zeer lichte energie uit.

In een door hem geleide fantasie liepen we door een bos, op weg naar een boom op een grasveld. Bij het nabespreken bleek weer dat anderen beduidend meer hadden meegemaakt dan ik. Verschillende mensen hadden dieren ontmoet in het bos, en een man vertelde dat hij zichzelf had gezien, toen hij onder aan de boom omhooggekeken had. De laaghangende takken waren zijn baard, de top van de boom was zijn kruin. In plaats van de interpretatie van hun belevenissen aan mensen zelf te laten, onderwees Searching Deer ons. Een eekhoorn was bijvoorbeeld een mediator tussen de verschillende werelden, zoals de eekhoorn ook van boven naar beneden in bomen klimt.

Ook in de laatste workshop waaraan ik meedeed op het Eigentijdsfestival van 2004 stond de sjamanistische levensboom centraal. Altaiskaya Byelka, oprichtster en leidster van het Instituut van Siberisch Sjamanisme, verzorgde op zaterdagmiddag een workshop waarin we onder andere een techniek gebruikten om in onze familiegeschiedenis terug te gaan. Daar zouden we werken aan vervloekingen die ooit waren uitgesproken. Begeleid door Siberische trommels stapten we naar voren en naar achteren om zeven generaties te healen.

De hevige emotionele uitbarstingen van sommige deelnemers vond ik zeer onprettig. Een vrouw was zo overweldigd dat ze bijna in de tent stond te braken. In plaats van haar gerust te stellen, zoals ik graag had gezien, omcirkelden de trommelaars haar, en voerden de druk verder op, om haar bij te staan in haar strijd tegen haar demonen. Na meer dan drie uur verliet ik uitgeput de tent. Meer sjamanistische workshops kon ik even niet meer verdragen. Ik besloot dan ook dat het genoeg was geweest, brak mijn tent op, pakte mijn tassen, en ging naar huis.

\section{Reflectie}

Mijn eerste veldwerkervaringen leerden me dat gematigde participatie mij meer zou liggen dan actieve participatie. Ik heb geen talent voor sjamanisme en ben, om een term van Max Weber te gebruiken, religiös unmusikalisch. Dat was niet per se problematisch, want mijn sjamanistische ervaringen zouden geen inzicht geven in de ervaringen van anderen. Wel kon ik hun interpretaties van ervaringen regis- 
treren door te luisteren naar de manieren waarop ze spraken of schreven over sjamanisme. En uitleg en verhalen over sjamanisme zijn overvloedig aanwezig: tijdens open dagen en bij losse workshops wordt veel uitgelegd en websites van sjamanistische instituten zijn gevuld met teksten waarin niet alleen de vorm en inhoud van de eigen specifieke sjamanistische ideeën en praktijken worden verantwoord, maar ook de exclusieve expertise van docenten en de bronnen van hun sjamanistische kennis.

Hoezeer sjamanisme op het Eigentijdsfestival een betwist begrip is, werd ook duidelijk. De sjamanistische instituten definiëren sjamanisme anders, hun sjamanistische activiteiten verschillen aanzienlijk en de interpretaties van sjamanistische ervaringen variëren ook. Ze positioneren zichzelf ten opzichte van elkaar en ten opzichte van niet-sjamanistische esoterische praktijken, en ze verantwoorden hun interpretaties voortdurend.

Dit inzicht, gecombineerd met mijn eerste veldwerkervaringen, had grote gevolgen voor mijn onderzoek. Ik realiseerde me dat niet het participeren zelf, maar het observeren tijdens het participeren informatie opleverde. Bovendien wist ik nu dat sjamanisme in Nederland zo gevarieerd was dat actieve en intensieve participatie bij één sjamaneninstituut me geen inzicht zou opleveren in sjamanisme in Nederland. Ik koos er daarom voor om mijn aandacht te richten op de verschillende manieren waarop sjamanisme vorm, inhoud en betekenis krijgt in Nederland, en op de manieren waarop autoriteiten hun eigen kennis over sjamanisme autoriseren en legitimeren.

Het begrippenapparaat van Pierre Bourdieu was daarvoor goed bruikbaar (Bourdieu, 1984). Ik ging me richten op het veld van sjamanisme als een geheel van relaties met een specifieke structuur. Ik zou het geloofsuniversum en de specifieke, deels onbewuste, regels in kaart brengen, en de interne strijd om belangrijke posities op het veld interpreteren door te kijken naar de vormen van kapitaal die in het sjamanistische veld waarde hebben. De manieren waarop dominante spelers prestige, status of autoriteit claimen, kon ik uitdrukken als hun gebruik van symbolisch kapitaal. Daarnaast richtte ik me op hun habitus, oftewel de door socialisatie bereikte vanzelfsprekende schema's die de waarneming en het handelen van mensen in het veld vormgeven.

Verstehen bleef daarbij het doel. Ik wilde nog steeds uitvinden 'what the devil they think they are up to', maar zoals Clifford Geertz al betoogde, daarvoor is meevoelen niet nodig (Geertz, 1973). Voor het ontwikkelen van een praktisch gevoel voor sjamanisme zat mijn eigen sceptische habitus me in de weg. Participeren bleef nuttig, want via veldwerk kon ik de logica van het veld doorgronden: zo kon ik mensen observeren die het spel goed beheersen. Hun taal, symbolen en gebruiken gaven mij inzicht in hun sjamanistische zelfpresentatie. Als succesvolle spelers belichamen zij de kennis van het spel, en gebruiken ze de relevante troeven. Dat gaf mij zicht op hun zelflegitimerende verbeelding, want dat is waarmee autoriteiten in het veld hun waarheidsclaims aanvaardbaar maken voor hun publiek.

Mijn perspectief verschoof nog meer na verdere bestudering van literatuur over sjamanisme. Dit leerde me dat sjamanisme ook in wetenschappelijke velden een betwist begrip is: door antropologen, folkloristen, theologen, godsdienstwetenschappers en anderen is en wordt het op heel verschillende manieren gebruikt. Ik 
besloot daarom om de uiteenlopende definities en interpretaties van sjamanisme genealogisch te ordenen in een historisch verhaal over allerhande onderzoekers die, gestuurd door hun habitus en de worsteling met anderen, een visie op sjamanisme ontwikkelden. Het zorgde ervoor dat ik in mijn proefschrift relatief weinig aandacht besteedde aan Nederlandse sjamanistische praktijken.

In het veld van sjamanisme werden de resultaten van mijn worsteling met sjamanisme niet aanvaard. Dat is logisch, want ik schreef mijn proefschrift vanuit mijn positie in het wetenschappelijke veld, gestuurd door mijn sceptische habitus, en die is anders dan de habitus van mensen die sjamanisme beoefenen (Boekhoven, 2011). In een recensie schreef een sjamaan dat ze mijn proefschrift wel op een bokswedstrijd vond lijken, wetenschap versus spiritualiteit. Die lezing klopt niet, want mijn proefschrift is bovenal een bijdrage aan een interne wetenschappelijke strijd.

Mijn sceptische habitus stuurde ook mijn benadering van wetenschappelijke kennis over sjamanisme. Ik constateerde dat zeer bepalende interpretaties van sjamanisme geconstrueerd zijn door onderzoekers met een contextgebonden religieuze, politieke, psychedelische, romantische, nationalistische en/of andere habitus. Hun academische zelflegitimerende verbeelding weerhield me er niet van hun constructie van kennis even kritisch te interpreteren als de productie van kennis in het veld van sjamanisme. Wetenschappelijk of niet, alle schakeringen in het veelkleurig palet aan interpretaties zijn voortbrengselen van strategisch handelende personen in specifieke netwerken van relaties. Zoals Bourdieu al schreef: 'the real is relational'.

\section{Literatuur}

Boekhoven, J.W. (2011). Genealogies of Shamanism: Struggles for power, charisma and authority. Eelde: Barkhuis Publishing.

Bourdieu, P. (1984). Distinction: A social critique of the judgement of taste. London: Routledge.

Geertz, C. (1973). Thick description: Toward an interpretive theory of culture. In C. Geertz, The interpretation of cultures: Selected essays (pp. 3-30). New York: Basic Books. 